\title{
Assistência de enfermagem à pacientes com úlceras venosas atendidos em um Hospital Universitário: Um relato de experiência
}

\author{
Nursing care for patients with venous ulcers treated at a University Hospital: Experience report \\ Atención de enfermería a pacientes con úlceras venosas atendidos en un Hospital Universitario: \\ Relato de experiencia
}

Recebido: 27/03/2021 | Revisado: 04/04/2021 | Aceito: 04/04/2021 | Publicado: 15/04/2021

Aclênia Maria Nascimento Ribeiro ORCID: https://orcid.org/0000-0002-5582-9663 Universidade Federal do Piauí, Brasil E-mail: aclennya@hotmail.com

Gabriela Oliveira Parentes da Costa

ORCID: https://orcid.org/0000-0001-9473-8986 Instituto Federal de Educação, Ciência e Tecnologia do Maranhão, Brasil E-mail: gabiparents@hotmail.com

Roxana Mesquita de Oliveira Teixeira Siqueira ORCID: https://orcid.org/0000-0001-9549-2068 Hospital Universitário da Universidade Federal do Piaú, Brasil E-mail: roxanasiqueira@hotmail.com

Francisca das Chagas Sheyla Almeida Gomes Braga ORCID: https://orcid.org/0000-0001-5646-0100 Hospital Universitário da Universidade Federal do Piauí, Brasil E-mail: sheylagomesbraga@gmail.com

Yara Maria Rêgo Leite

ORCID: https://orcid.org/0000-0002-4868-2624 Hospital Universitário da Universidade Federal do Piauí, Brasil E-mail: yara_leite189@hotmail.com

Verônica Elis Araújo Rezende ORCID: https://orcid.org/0000-0001-9076-3375 Universidade Federal do Piauí, Brasil

E-mail: veronicaelisrezende@yahoo.com.br

Pâmela Caroline Guimarães Gonçalves ORCID: https://orcid.org/0000-0003-1292-8386

Centro Universitário Internacional, Brasil E-mail:pamelaenfermeira@gmail.com Carolina Silva Vale

ORCID: https://orcid.org/0000-0001-8269-9705 Hospital Universitário da Universidade Federal do Piauí, Brasil E-mail: carol.vale.enf@hotmail.com

Maria Lailda de Assis Santos

ORCID: https://orcid.org/0000-0002-5521-5151 Universidade Estadual do Piauí, Brasil E-mail: laildasantos@hotmail.com

Ravena de Sousa Alencar Ferreira ORCID: https://orcid.org/0000-0001-7311-2212 Universidade Federal do Piauí, Brasil E-mail: ravenaa89@gmail.com

Diana Nogueira Villa Jatobá ORCID: https://orcid.org/0000-0003-4346-8335 Centro Universitário UNINOVAFAPI, Brasil E-mail: devilla@hotmail.com

Ana Rachel Cavalcante Araújo Fernandes ORCID: https://orcid.org/0000-0003-0913-3451 Universidade de Fortaleza, Brasil

E-mail: rachel_cavalcante@ @otmail.com

Mara Cléssia de Oliveira Castro ORCID: https://orcid.org/0000-0002-1808-7963 Centro Universitário UNINOVAFAPI, Brasil E-mail: maraclessia@hotmail.com 


\begin{abstract}
Resumo
Introdução: Entre as doenças crônicas que mais acometem os adultos estão as úlceras venosas crônicas, que são consideradas uma síndrome que causa perda tecidual, capaz de atingir o tecido subcutâneo e adjacentes, principalmente nas extremidades dos membros inferiores. Essas lesões podem permanecer por muito tempo e ter uma recorrência frequente, levando de meses a anos, para que ocorra a epitelização tecidual. Metodologia: Trata-se de um relato de experiência que descreve aspectos vivenciados por residentes de enfermagem, na oportunidade do ingresso em um Programa de Residência Multiprofissional em Saúde de uma Universidade Federal do Nordeste, cujas atividades práticas foram desenvolvidas em diversos setores de um hospital universitário, incluindo o ambulatório de estomaterapia. Resultados e discussões: As atividades desenvolvidas no ambulatório de estomaterapia pelas residentes foram diversas e variaram desde a realização dos curativos até o acolhimento ao paciente nas consultas de enfermagem, fornecendo orientações para o autocuidado e para o correto manejo das úlceras venosas, incentivo a alimentação saudável e manutenção do tratamento e apoio aos pacientes e familiares permitindo assim um atendimento integral. Conclusão: Assim, acredita-se que a experiência permitiu a consolidação de conhecimentos teóricos e práticos, ganho de autonomia, desenvolvimento de habilidades e destreza manual durante a realização dos curativos, avaliando e investigando os aspectos físicos e sistêmicos que interferem no processo de cicatrização, e ainda, constituiu-se como uma oportunidade favorável para a aplicação da SAE a nível ambulatorial.
\end{abstract}

Palavras-chave: Cuidados de enfermagem; Úlcera varicosa; Assistência ambulatorial.

\begin{abstract}
Introduction: Among the chronic diseases that most affect adults are chronic venous ulcers, which are considered a syndrome that causes tissue loss, capable of reaching the subcutaneous and adjacent tissue, especially in the extremities of the lower limbs. These lesions can remain for a long time and have a frequent recurrence, taking from months to years, for tissue epithelialization to occur. Methodology: This is an experience report that describes aspects experienced by nursing residents, in the opportunity to enter a Multiprofessional Residency Program in Health at a Federal University of the Northeast, whose practical activities were developed in different sectors of a university hospital, including the stomatherapy outpatient clinic. Results and discussions: The activities developed by the residents in the stoma therapy outpatient clinic were diverse and varied from the dressing to welcoming the patient in nursing consultations, providing guidance for self-care and the correct management of venous ulcers, encouraging healthy eating. and maintenance of treatment and support for patients and family members, thus allowing comprehensive care. Conclusion: Thus, it is believed that the experience allowed the consolidation of theoretical and practical knowledge, gain of autonomy, development of skills and manual dexterity during the dressing, evaluating and investigating the physical and systemic aspects that interfere in the healing process, and yet, it was a favorable opportunity for the application of SAE on an outpatient basis.
\end{abstract}

Keywords: Nursing care; Varicose ulcer; Outpatient care.

\title{
Resumen
}

Introducción: Entre las enfermedades crónicas que más afectan a los adultos se encuentran las úlceras venosas crónicas, las cuales se consideran un síndrome que ocasiona pérdida de tejido, capaz de llegar al tejido subcutáneo y adyacente, especialmente en las extremidades de los miembros inferiores. Estas lesiones pueden permanecer durante mucho tiempo y tener una recurrencia frecuente, que tarda de meses a años, para que se produzca la epitelización tisular. Metodología: Se trata de un relato de experiencia que describe aspectos vividos por residentes de enfermería, en la oportunidad de ingresar a un Programa de Residencia Multiprofesional en Salud en una Universidad Federal del Nordeste, cuyas actividades prácticas se desarrollaron en diferentes sectores de un hospital universitario, incluida la estomaterapia. clínica de consulta externa. Resultados y discusiones: Las actividades desarrolladas por los residentes en el ambulatorio de estomaterapia fueron diversas y variadas desde el apósito hasta la acogida del paciente en las consultas de enfermería, la orientación para el autocuidado y el correcto manejo de las úlceras venosas, fomentando una alimentación saludable. mantenimiento del tratamiento y apoyo a los pacientes y familiares, permitiendo así una atención integral. Conclusión: Así, se cree que la experiencia permitió la consolidación de conocimientos teóricos y prácticos, la obtención de autonomía, el desarrollo de habilidades y destreza manual durante el vendaje, evaluando e investigando los aspectos físicos y sistémicos que interfieren en el proceso de curación, y sin embargo, fue una oportunidad favorable para la aplicación de SAE de forma ambulatoria.

Palabras clave: Atención de enfermería; Úlcera varicosa; Atención ambulatoria.

\section{Introdução}

Alguns fatores estão diretamente relacionados com o crescimento da expectativa de vida de uma população, dentre eles, está o aumento dos casos de doenças crônicas. Esse cenário exige um olhar holístico dos profissionais no tocante aos cuidados e promoção da saúde. As ações devem ser voltadas para redução dos impactos que as patologias causam no paciente, propiciando qualidade de vida aos mesmos (Nunes \& Queiros, 2017). 
Considerando que na terceira idade, as doenças crônicas não transmissíveis são as que apresentam maiores taxas de incidência e prevalência e, frequentemente, causam mortes ou incapacidades evitáveis aos adultos, o processo de adoecimento deve ser pesquisado e interpretado para que o cuidado a esta faixa etária seja efetivo (Joaquim et al., 2018).

Entre as doenças crônicas que mais acometem os adultos estão as úlceras venosas crônicas, que para Oliveira, Nogueira e Abreu (2012), são consideradas uma síndrome que causa perda tecidual, capaz de atingir o tecido subcutâneo e adjacentes, principalmente nas extremidades dos membros inferiores. Essas lesões podem permanecer por muito tempo e ter uma recorrência frequente, levando de meses a anos, para que ocorra a epitelização tecidual.

Nesse sentido, é relevante enfatizar que as úlceras venosas são um problema grave para a saúde do paciente, uma vez que sua ocorrência acompanha o crescimento da população idosa, agravando-se com a idade avançada (Medeiros et al., 2013).

Segundo Evangelista et al. (2012), as úlceras venosas afetam a saúde dos indivíduos de tal forma que podem causar impacto social e econômico, uma vez que podem ser responsáveis pelo afastamento das atividades executadas diariamente e até das atividades laborais, podendo resultar em aposentadoria precoce.

Sabe-se que 3\% da população brasileira são acometidas de úlceras venosas e quando se trata de pacientes diabéticos, esse número sobe para 10\%. Dentre estes, 4 milhões desenvolve algum tipo de complicação durante o processo de cicatrização (Cruz, Carvalho \& Melo, 2017). Nessa perspectiva, o estudo objetivou descrever a experiência de residentes de enfermagem durante a assistência a pacientes com úlceras venosas.

\section{Metodologia}

Esta pesquisa consiste em um relato de experiência que descreve aspectos vivenciados por residentes de enfermagem na oportunidade do ingresso em um Programa de Residência Multiprofissional em Saúde de uma Universidade Federal do Nordeste, cujas atividades práticas foram desenvolvidas em diversos setores de um hospital universitário, incluindo o ambulatório especializado no tratamento de feridas. Trata-se portanto, de um olhar qualitativo, que abordou a problemática desenhada a partir de métodos descritivos e observacionais.

O relato de experiência, segundo Cavalcante e Lima (2012), permite a reflexão de ações executadas, seja por um indivíduo ou por um grupo, onde são abordadas orientações ou medidas pertinentes a uma realidade e, posteriormente, relatadas de forma descritivas para uma comunidade cientifica.

A residência permitiu a vivências prática em diversos setores desse hospital, com destaque ao ambulatório de estomaterapia, no qual as residentes permaneceram por um período de 30 dias, acompanhadas por preceptores do programa.

É importante ressaltar que o serviço de estomaterapia disponibilizado por essa instituição iniciou-se no ano de 2015, ofertando assistência multiprofissional voltada a pacientes com estomias e lesões de pele, sendo ofertado posteriormente também atendimentos relacionados à incontinência. No entanto, quanto aos atendimentos diários, predomina-se o tratamento de feridas, incluindo as úlceras venosas.

\section{Resultados e Discussão}

No decorrer do desenvolvimento das atividades no ambulatório de estomaterapia, as residentes desempenharam funções diversas que variaram desde a realização dos curativos até o acolhimento ao paciente nas consultas de enfermagem, fornecendo orientações para o autocuidado e para o correto manejo das úlceras venosas, incentivo a alimentação saudável e manutenção do tratamento e apoio aos pacientes e familiares permitindo assim um atendimento integral.

Inicialmente, era realizada a consulta de enfermagem utilizando a sistematização da assistência de enfermagem, destacando os principais diagnósticos encontrados e traçando as intervenções necessárias para cada paciente. 
Nesse primeiro momento era realizado a anamnese e exame físico do paciente, atentando-se para os membros inferiores e análise da lesão. Convém destacar que essa assistência se dava de uma forma integral e multidisciplinar, envolvendo os demais membros da equipe de saúde, como médicos, psicólogos, nutricionistas e terapeuta ocupacional, quando necessário.

Segundo Aguiar et al. (2016), o enfermeiro tem um importante papel na execução dos cuidados prestados ao paciente com úlcera venosa, pelo fato de este ter contato direto e diário com o mesmo. Assim, é importante que o profissional sistematize a assistência e não deixe de realizar a avaliação do cuidado.

Nesse contexto, considerando a complexidade e a longa duração do tratamento, é importante enfatizar que o conhecimento técnico da equipe, bem como o conhecimento específico sobre a doença, contribui para melhora do quadro do paciente, devendo esta ser uma responsabilidade interdisciplinar, articulada entre todos os níveis da assistência por onde esse paciente percorrerá (Cruz, Carvalho \& Melo, 2017).

Durante as consultas de enfermagem, observou-se que os pacientes ainda apresentavam dúvidas quanto ao tratamento das lesões, apresentando-se apreensivos, por vezes angustiados. Assim, esse momento fornecia uma oportunidade para sanar as dúvidas dos pacientes e familiares, permitindo uma melhor assimilação e adesão do tratamento a ser realizado.

Quanto à adesão ao tratamento, um estudo realizado por Green et al. (2013), evidenciou que, quanto mais longo for o tempo do tratamento, maior a probabilidade de o paciente desistir do mesmo. $\mathrm{O}$ autor percebeu que os pacientes ficam desestimulados e com a impressão de que a cura é pouco provável ou até mesmo impossível.

Nesse sentido, percebe-se que a adesão terapêutica é um fator relevante para a cicatrização em menor tempo (Weller, Buchbinder \& Johnston, 2013). Contudo, essa adesão terapêutica é um dos desafios entre os portadores desse tipo de lesão (Liberato et al., 2017).

Além das consultas de enfermagem, as residentes realizam curativos diários das úlceras venosas. Esses procedimentos eram realizados juntamente com os preceptores, o que proporcionava uma oportunidade de troca de conhecimento e aquisição de habilidades no manuseio das coberturas e realização adequada dos curativos.

Para Campoi et al. (2019), a efetividade do tratamento de úlcera venosa é descrita em três condutas: inicia com o tratamento da estase venosa, prescrevendo-se o repouso e a terapia compressiva, juntamente com terapias tópicas, e coberturas locais, que absorvam o exsudato e a previna recidivas, de forma a manter o leito da ferida úmido e limpo.

Nesse sentido, as coberturas tópicas utilizadas no ambulatório variavam conforme as características das lesões, sendo as mais utilizadas: gaze rayon impregnada com petrolatum ou Ácidos Graxos Essenciais (A.G.E.), compressas ou espumas impregnadas com Poliexamida Biguanina (PHMB) e coberturas à base de carvão ativado, alginato ou hidrofibra com ou sem prata. Associada a essas coberturas, a instituição disponibilizava a Bota de Unna como terapia compressiva.

Segundo Macedo et al. (2018), as terapias compressivas são utilizadas para diminuir a hipertensão e minimizar seus efeitos na macro e micro circulação do local adoecido. Na primeira etapa, contribui para o retorno venoso profundo, o que diminui o refluxo patológico. $\mathrm{N}$ segundo momento, diminui a perca de líquidos e moléculas dos capilares e vênulas. Considerada como o principal cuidado aos pacientes com úlcera venosa, a terapia compressiva, pode promover a cicatrização e prevenir recidivas. A terapia pode ainda, aumentar a compressão, favorecer a drenagem e contribuir para o suporte venoso, favorecendo a cicatrização da úlcera.

Durantes as práticas de realização dos curativos, as residentes obtiveram habilidade e autonomia no uso da bota de Unna, favorecendo assim a aquisição de conhecimentos para qualificação da assistência a pacientes com úlceras venosas, além de desenvolver raciocínio crítico e reflexivo diante dessas lesões de pele. 


\section{Conclusão}

A experiência vivenciada em um ambulatório especializado no tratamento de feridas constituiu-se como um campo que oportunizou uma gama de conhecimento para as residentes, visto que permitiu os desenvolvimentos de competências indispensáveis no tratamento das úlceras venosas, tendo em vista que são lesões frequentes em diversos cenários de atenção à saúde.

Os cuidados realizados a esses pacientes contribuíram para o bom estado físico e emocional, proporcionando aos profissionais a aplicação das práticas de enfermagem e inúmeras experiências no âmbito institucional.

Além disso, houve a consolidação de conhecimentos teóricos e práticos, ganho de autonomia, desenvolvimento de habilidades e destreza manual durante a realização dos curativos, avaliando e investigando os aspectos físicos e sistêmicos que interferem no processo de cicatrização, e ainda, constituiu-se como uma oportunidade favorável para a aplicação da SAE a nível ambulatorial.

Assim, acredita-se que estudos com esse enfoque podem servir como fonte de incentivo para novas pesquisas relacionados à temática abordada, considerando que essas informações subsidiarão novas experiências, permitindo ao paciente uma assistência de qualidade e especializada.

\section{Referências}

Aguiar, A. C. S. A. et al. (2016). Repercussões sociais vivenciadas pela pessoa idosa com úlcera venosa. Revista Gaúcha de Enfermagem, 37(3):30-38.

Campoi, A. L. M. et al. (2019). Assistência de enfermagem a pacientes com feridas crônicas: um relato de experiência. $R E F A C S, 7(2): 248-255$.

Cavalcante, B. L. L \& Lima, U. T. S. (2012). Relato de experiência de uma estudante de Enfermagem em um consultório especializado em tratamento de feridas. J Nurs Health, Pelotas (RS),1(2):94-103.

Cruz, L. A., Carvalho, F. L. O., \& Melo, A. U. C. (2017). Assistência de enfermagem a pacientes com úlceras venosas. Revista Saúde em Foco, 10(9):17-25. Evangelista, D. G. et al. (2012). Impacto das feridas crônicas na qualidade de vida de usuários da estratégia de saúde da família. Rev Enferm Cent-Oeste Min, 2(2).

Green, J. et al. (2013). Patient perspectives of their leg ulcer journey. Journal of wound care, 22(2):58-66.

Joaquim, F. L. et al. (2018). Impact of venous ulcers on patients' quality of life:an integrative review. Rev Bras Enferm,71(4):2021-2029.

Liberato, S. M. D. et 1. (2017). Adesão ao tratamento de pessoas com úlceras venosas atendidas na atenção primária à saúde. Aquichan, 17(2):128-139.

Macedo, E. A. B. et al. (2018). Tratamento hospitalar de pessoas com membros inferiores com varizes e ulceras: pesquisa no DATASUS. Revista Eletrônica da FAINOR, 11(3):684-698.

Medeiros, A. B. A. et al. (2013). Perfil socioeconômico de pessoas com úlceras venosas: aspectos relevantes para a enfermagem. Rev de Enferm UFPE online. 7(8):5220-5224.

Nunes, H. J. M. \& Queiros, P. J. P. (2017). Patient with stroke: hospital discharge planning, functionality and quality of life. Rev Bras Enferm, 70(2):433-42.

Oliveira, B. G. R. B., Nogueira, G. A. \& Abreu, A. M. (2012). Caracterização dos pacientes com úlcera venosa acompanhados no Ambulatório de Reparo de Feridas. Revista Eletrônica de Enfermagem, 14(1):156-63.

Weller, C. D., Buchbinder, R., \& Johnston, R. V. (2013). Interventions for helping people adhere to compression treatments for venous leg ulceration. Cochrane Database of Systematic Reviews, 1(9). 